\title{
Mental Health Literacy and Help-Seeking Behaviours Among Undergraduate Pharmacy Students in Abha, Saudi Arabia
}

\author{
Mona Almanasef (D) \\ Department of Clinical Pharmacy, \\ College of Pharmacy, King Khalid \\ University, Abha, Saudi Arabia
}

This article was published in the following Dove Press journal: Risk Management and Healthcare Policy

Background: The serious mental health problems experienced by university students could have a negative impact on their long-term mental, social and physical health as well as their academic achievements. The ability to recognise a condition, and knowledge about mental health issues and sources of help, are among the factors influencing help-seeking behaviour in young individuals. This study was conducted to examine the mental health literacy among undergraduate pharmacy students and to assess whether mental health literacy is linked to a stronger intention to seek help.

Methods: This prospective cross-sectional study used an online self-administered questionnaire. A total of 271 pharmacy students at King Khalid University completed the questionnaire and agreed to participate in the study.

Results: The mental health literacy in the current study $(M=112.53)$ was found to be lower than that reported in international research using the MHLS. Students with no history of mental health issues scored significantly higher in help-seeking behaviours from informal sources $(M=23.65, \mathrm{SD}=6.88)$ than those with a previous history $(M=19.03, \mathrm{SD}=7.58), F(1$, $269)=11.76, p=0.001$. The study revealed a significant positive correlation between mental health literacy and help-seeking behaviours $r(271)=0.26, p<0.01$.

Conclusion: This study demonstrates that there is a positive correlation between mental health literacy and help-seeking behaviours. Implementing appropriate interventions could be a key priority in improving the mental health literacy and help-seeking behaviour of students.

Keywords: mental health literacy, help-seeking behaviours, pharmacy students, Saudi Arabia

\section{Introduction}

Mental Health Literacy (MHL) is described as the knowledge of, and attitude towards, mental health that assists in recognising, managing and preventing mental health disorders. ${ }^{1}$ University students experience immense vulnerability associated with mental health problems. ${ }^{2}$ These difficulties could interfere with everyday life and range on the spectrum from minor concerns, such as stress and worry, to more serious long-term mental health conditions, such as anxiety and depression. ${ }^{2}$ A large-scale web-based US study revealed that $17.3 \%$ of university students suffer from depression, 7\% from generalised anxiety disorder and 6.3\% from suicide ideation. $^{3}$ The serious mental health problems experienced by university students could have a negative impact on their long-term mental, social and physical health as well as their academic achievements. ${ }^{2}$
Correspondence: Mona Almanasef College of Pharmacy, King Khalid University, P.O. Box 960, Abha, 61421, Saudi Arabia

Email malmanasaef@kku.edu.sa
Risk Management and Healthcare Policy 202I:|4 I28I-1286 
Students in the health profession disciplines, including pharmacy students, encounter a high level of stress due to academic overload and other factors that can have a negative impact on their mental health and well-being. ${ }^{4}$ Smith and Shochet suggested a positive correlation between mental health literacy and help-seeking behaviour in university students. ${ }^{5}$ University students have limited mental health literacy skills to assist them in recognising mental health issues and seeking professional help when needed. ${ }^{2}$ The ability to recognise a condition and knowledge about mental health issues and sources of help are among the factors influencing the help-seeking of young individuals. ${ }^{6}$

Help-seeking has been defined as "a behaviour of actively seeking help from other people" (p. 3), and this involves discussing personal issues with another person for support and to receive guidance. ${ }^{7}$ The sources of help are classified into formal - such as those who have a professional degree in a relevant field - and informal, such as parents or other family members. ${ }^{7}$ The most commonly reported barriers to seeking help were fear of stigma, embarrassment, poor mental health literacy and a preference for self-reliance. ${ }^{7-12}$

The prevalence of mental illnesses among the Saudi population has been estimated to be around $18.2 \%$, which is no different from the prevalence of diabetes mellitus. ${ }^{13}$ Mahfouz et al conducted a cross-sectional study to examine mental health literacy among undergraduate students in Jazan, Saudi Arabia. Their study revealed that most students had an intermediate level of mental health literacy. However, about half of the participants showed a negative attitude towards mentally ill people and the management of mental illnesses. ${ }^{13}$

Evidence about mental health literacy and help-seeking behaviours among undergraduate pharmacy students is limited and, to the best of our knowledge, there no study has been conducted to assess this in Saudi Arabia. Hence, this study was conducted to examine the mental health literacy among undergraduate pharmacy students and to assess whether it is linked to a stronger intention to seek help.

\section{Methods}

\section{Study Design and Setting}

A prospective cross-sectional study using an online selfadministered questionnaire. The study took place in the college of pharmacy, King Khalid University (KKU), Abha, Saudi Arabia, between February and April 2020.
$\mathrm{KKU}$ is a public university located in the southern region of Saudi Arabia, and it includes a total of 29 colleges and enrols more than 60,000 students. ${ }^{14}$

\section{Study Participants}

The study participants were students enrolled for the undergraduate pharmacy programme (PharmD and BPharm) in the second term of the academic year 2019/ 2020 who were above the age of 18 years. Raosoft ${ }^{\circledR}$ software was used to calculate the minimum recommended sample size. This was estimated to be 297 participants based on a population size of 1,300 students, with a $5 \%$ margin of error, a $95 \%$ confidence level and a $50 \%$ response distribution.

\section{Data Collection}

An online questionnaire was created using Google forms (a survey administration software). An invitation to participate in the study was sent to all potential participants on their university email address. Attempts to maximise the response rate involved course instructors inviting students to participate at the end of lectures.

\section{Materials}

The questionnaire was adapted from previous research, ${ }^{1,2,15}$ and it consisted of three sections. Section one was designed to collect demographic information, ie, age, gender, academic year and previous diagnosis of mental health problems. The second and third sections of the questionnaire were adapted from the Mental Health Literacy Scale (MHLS) ${ }^{1,2}$ and the general help-seeking questionnaire (GHSQ). ${ }^{2,15}$ The questionnaire was distributed in the Arabic language. The original version of the questionnaire was initially prepared in English Language and then translated into Arabic which is the first language of the study participants. In order to ensure the validity of the translation, back-translation technique was adopted. The translation process was undertaken by three translators who have excellent proficiency in both languages and who are pharmacy academics. The English questionnaire was translated into Arabic first by the first translator. The second translator back-translated the translated version into the English language. The original and the backtranslated versions were compared by the third translator and amendments were suggested. The MHLS is a previously validated tool with good internal (Cronbach's alpha $=0.873$ ) and test-retest reliability ( $\mathrm{r}$ (69) $=0.797, P<0.001)$ that measures the individual's level 
of mental health literacy. ${ }^{1}$ It consists of a total of 35 items that measure the following: the ability to identify disorders (8 items), knowledge about seeking information (4 items), knowledge of risk factors and causes ( 2 items), knowledge of self-treatment (2 items), knowledge of professional support available (3 items) and attitudes towards promoting positive mental health or help-seeking behaviour (16 items). ${ }^{1}$ The minimum possible score in MHLS is 35 points, while the maximum possible score is 160 points, which reflects the highest level of mental health literacy. ${ }^{2}$ The last section of the questionnaire, which was adapted from the GHSQ, evaluates help-seeking behaviour when encountering mental health issues. Specifically, it requests potential participants to indicate their level of intention to seek help from a number of pre-determined individuals, such as a friend or a psychologist, if they experience a personal or emotional difficulty on a scale from 1 (extremely unlikely) to 7 (extremely likely). ${ }^{2,15}$ A higher score reflects a stronger intention to seek help when facing mental health problems. The GHSQ has demonstrated good test-retest reliability $(\mathrm{r}=0.92)$ and it was significantly positively correlated to actually seeking counselling $(r(218)=0.17, p<0.05) .^{2,15}$

\section{Ethical Considerations}

Ethical approval was granted by the King Khalid University Research Ethics Committee, approval reference (HAPO-06-B-001). Participation in the study was voluntary and potential participants had the right to decline the invitation to participate without any penalty. Identifiers such as Email addresses and IP addresses were not collected. The data gathered will not be used to identify participants and are kept securely by the researcher. All participants provided informed consent. The cover page of the questionnaire displayed a participant information sheet, with a statement indicating that submission of a completed questionnaire implies consent to participate. Another statement explained that "by entering the questionnaire, I indicate that I have read the information provided and agree to participate". This study was conducted in accordance with the Declaration of Helsinki.

\section{Statistical Analysis}

The analysis of the data collected was performed using SPSS version 26.0 for Mac. Descriptive statistics were used to summarise the characteristics of the participants, and the scores for MHLS and GHSQ. Analyses of variance were used to explore differences in mental health literacy and help-seeking behaviours among the different groups of students, ie, according to gender, previous diagnosis of mental health problems and the academic year. Pearson's correlations test was used to examine the relationship between mental health literacy and help-seeking behaviour among the students. The level of significance was set at an alpha level equal to 0.05 for all analyses.

\section{Results}

A total of 271 students returned the questionnaire and agreed to participate in the study. $29.5 \%(n=80)$ of them were male and $70.5 \%(n=191)$ were female. The survey response rate based on the minimum recommended sample size was $91.25 \%$. Somewhat more than half (52.4\%) of the participants were in the third and fourth year, about a third $(30.3 \%)$ were in the first and second year, and the remaining $17.3 \%$ were interns. A total of $11.1 \%$ of the participants indicated that they had been previously diagnosed with a mental health problem. The demographic data of the participants are listed in Table 1.

The findings from the mental health literacy scale revealed a mean score of $112.53(\mathrm{SD}=12.64$, range $=80-141$, 95\% CI=111.02-114.04). The results of the MHLS were normally distributed as indicated by Skewness $(-0.048$, $\mathrm{SE}=0.148)$, Kurtosis $(-0.620, \mathrm{SE}=0.295)$ and the ShapiroWilk test (0.991, $\mathrm{df}=271, p=0.083)$.

Female students scored significantly higher ratings of mental health literacy $(M=113.77, \mathrm{SD}=12.70)$ than male students $(M=109.58, \quad \mathrm{SD}=12.04), \quad F \quad(1,269)=6.336$, $p=0.012$. No significant differences in mental health

Table I Demographic Information of the Participants $(n=27$ I)

\begin{tabular}{|l|l|}
\hline Characteristics & n (\%) \\
\hline $\begin{array}{l}\text { Mean age (SD) } \\
22.16(\text { I.5I) }\end{array}$ & $27 I(100)$ \\
\hline $\begin{array}{l}\text { Gender } \\
\text { Male }\end{array}$ & $80(29.5)$ \\
Female & $191(70.5)$ \\
\hline $\begin{array}{l}\text { Academic year } \\
\text { Year I }\end{array}$ \\
Year 2 & $43(15.9)$ \\
Year 3 & $39(14.4)$ \\
Year 4 & $66(24.4)$ \\
Year 5 (intern) & $76(28.0)$ \\
\hline Previous diagnosis of mental health problem & $47(17.3)$ \\
Yes & \\
No & $30(11.1)$ \\
\hline
\end{tabular}


literacy were observed between students in the first year $(M=110.58, \quad \mathrm{SD}=11.71), \quad$ second year $\quad(M=111.51$, $\mathrm{SD}=12.24)$, third year $(M=114.21, \quad \mathrm{SD}=12.58)$ or fourth year $(M=114.57, \quad \mathrm{SD}=12.98), \quad$ and interns $(M=109.51, \mathrm{SD}=12.87), F(4,266=1.79, p=0.13)$. The mental health literacy score for the students who indicated a previous history of mental health illness $(M=118.9$, $\mathrm{SD}=13.29$ ) was significantly higher than those who had no previous mental health problems $(M=111.74$, $\mathrm{SD}=12.35), F(1,269)=8.82, p=0.003$.

The findings from the general help-seeking questionnaire revealed a mean score of 36.47 ( $\mathrm{SD}=10.23$, range $=9-63,95 \%$ $\mathrm{CI}=35.25-37.70)$. The students revealed that they would most likely seek help for personal or emotional problems from a psychiatrist $(M=5.04, \mathrm{SD}=1.78)$ or a psychologist $(M=4.97$, $\mathrm{SD}=1.80)$ or a friend $(M=4.76, \mathrm{SD}=1.78)$. However, they would be less likely to seek help from a teaching faculty $(M=2.62, \mathrm{SD}=1.64)$ or a religious leader $(M=2.88, \mathrm{SD}=1.79)$ or a general practitioner $(M=3.32, \mathrm{SD}=1.73)$. Generally, there is no statistically significant difference in help-seeking behaviour between male $(M=37.1, \mathrm{SD}=9.96)$ and female students $(M=36.21, \mathrm{SD}=10.36), F(1,269)=0.43, p=0.51$. Likewise, there were no statistically significant differences observed between different academic years, $F(4,266)=1, p=0.41$.

The mean score of general help-seeking behaviour for students with no history of mental health issues $(M=37.10$, $\mathrm{SD}=9.92$ ) was significantly higher than those diagnosed with mental health problems $(M=31.43, \mathrm{SD}=11.45), F(1,269)$ $=8.41, p=0.004$. Specifically, students with no history of mental health issues scored significantly higher in helpseeking behaviours from informal sources $(M=23.65$, $\mathrm{SD}=6.88)$ than those with a previous history $(M=19.03$, $\mathrm{SD}=7.58), F(1,269)=11.76, p=0.001$. However, no statistically significant difference was found in help-seeking behaviours from formal sources between the two categories, $F(1$, $269)=1.47, p=0.226$. Around $25 \%(\mathrm{n}=67)$ of the participants indicated that they were unlikely to seek help when encountering a personal or emotional problem. However, 54.2\% $(n=147)$ reported that not seeking help was unlikely.

The findings showed a significant positive correlation between mental health literacy and help-seeking behaviours $r(271)=0.26, p<0.01$. This indicates that students with a higher mental health literacy score were more likely to seek help when encountering mental health issues.

\section{Discussion}

The main purpose of this cross-sectional study was to examine the mental health literacy and help-seeking behaviours among undergraduate students of a pharmacy institution in the southwest of Saudi Arabia. In addition, it aimed to assess whether mental health literacy was associated with a stronger intention to seek help when encountering emotional issues. Overall, the mental health literacy in the current study $(M=112.53)$ was found to be lower than that reported in international research using the MHLS. ${ }^{1,2}$ In an Australian study conducted with a sample of 372 first-year undergraduate students, the mean score was $127.38 .^{1}$ This was reported to be 122.88 in another study conducted with 379 university students in the United Kingdom. ${ }^{2}$ The findings from this study mirror those observed in the previous work in which female students and those who had a previous history of a mental illness demonstrated significantly higher levels of mental health literacy. ${ }^{2}$ Consistent with a previous study, the academic year was found to be an irrelevant factor in the mental health literacy of the students. ${ }^{2}$ Courses on mental disorders are offered to the pharmacy students involved in the current research in the third and fourth year of the academic programme. The topics covered include major depressive disorder, bipolar disorder, schizophrenia, anxiety disorders, eating disorders, and sleep disorders. These courses focus mainly on the pathophysiology of mental disorders as well as the pharmacotherapeutic management. Pharmacy curriculum could be improved further to include topics that improve the mental health literacy of the students and minimise the negative and stigmatising views toward persons with mental illness.

Around a quarter of the students in the current study demonstrated a reluctance to seek help when facing personal or emotional problems. The barriers to help-seeking among students reported in previous studies included fear of stigma, embarrassment, a preference for self-reliance, poor mental health literacy and poor awareness of existing services available for students. ${ }^{7-12}$ The current study did not aim to understand the factors that contribute to students' unwillingness to seek help when encountering emotional difficulties. However, the college could run regular mental health awareness campaigns or interventions that aim to reduce the stigma associated with mental illnesses and publicise the services available for students. Mental health support is available to the student participants through the college's advisory and mentoring unit which has a referral policy in place. Through this unit, the students can access the campus-based mental health clinic that is run by independent mental health professionals, ie, psychiatrists and psychologists.

The students indicated that they would be most likely to seek help from a psychiatrist, a psychologist or a friend. They 
would, however, be less likely to seek help from a teaching faculty, a religious leader or a general practitioner. What is surprising is that those students who had no previous history of mental health issues were more likely to seek help from informal sources compared to their peers with a previous history. This particular finding accords with our earlier observations, which showed that levels of mental health literacy were higher in students who had a pervious history of a mental health illness. Consistent with the previous literature, this research confirms that mental health literacy is positively correlated with help-seeking behaviours. ${ }^{1,2,5}$

The findings in this study are subject to a number of limitations. First, around two thirds of the participants were female and in their final years of the pharmacy programme. Thus, the results from male participants and those students in the first and second years of the pharmacy programme are underrepresented in this study. Second, the findings are limited by the use of a cross-sectional design which cannot establish causality. Students from a mental health-related discipline, eg, psychology would have served as valuable controls for our study participants. Another limitation is that the study was conducted at a single pharmacy institution in Saudi Arabia. Therefore, the generalisability of the findings is limited to those with a similar context.

\section{Conclusion}

The current study demonstrated that mental health literacy among the undergraduate pharmacy students at KKU is lower than that among students in Western countries. Higher levels of mental health literacy were observed among female students and those who had a previous history of a mental illness. The preferred sources for helpseeking were a psychiatrist, a psychologist or a friend. However, seeking help from a teaching faculty, a religious leader or a general practitioner was less favoured by the students. The level of mental health literacy in the current study was positively correlated with help-seeking behaviours. Implementing interventions that aim to improve the mental health literacy and help-seeking behaviours of students should be a key priority.

\section{Acknowledgments}

The authors would like to thank the Scientific Deanship at King Khalid University for their administrative and technical support.

\section{Disclosure}

The author reports no conflicts of interest in this work.

\section{References}

1. O'Connor M, Casey L. The Mental Health Literacy Scale (MHLS): a new scale-based measure of mental health literacy. Psychiatry Res. 2015;229(1-2):511-516. doi:10.1016/j.psychres.2015.05.064

2. Gorczynski P, Sims-Schouten W, Hill D, Wilson JC. Examining mental health literacy, help seeking behaviours, and mental health outcomes in UK university students. J Ment Health Train Educ Pract. 2017;12(2):111-120. doi:10.1108/JMHTEP-05-2016-0027

3. Eisenberg D, Golberstein E, Hunt JB. Mental health and academic success in college. BE $J$ Econ Anal Policy. 2009;9(1):1-37. doi:10.2202/1935-1682.2191

4. Fischbein R, Bonfine N. Pharmacy and medical students' mental health symptoms, experiences, attitudes and help-seeking behaviors. Am J Pharm Educ. 2019;83(10):7558. doi:10.5688/ajpe7558

5. Smith CL, Shochet IM. The impact of mental health literacy on help-seeking intentions: results of a Pilot Study with First Year Psychology Students. Int J Ment Health Promot. 2011;13(2):14-20. doi:10.1080/14623730.2011.9715652

6. Amarasuriya SD, Jorm AF, Reavley NJ. Depression literacy of undergraduates in a non-western developing context: the case of Sri Lanka Psychiatry. BMC Res Notes. 2015;8(1):593. doi:10.1186/s13104-0151589-7

7. Gebreegziabher Y, Girma E, Tesfaye M. Help-seeking behavior of Jimma university students with common mental disorders: a cross-sectional study. PLoS One. 2019;14(2):e0212657. doi:10.1371/journal.pone.0212657

8. Ey S, Henning KR, Shaw DL. Attitudes and factors related to seeking mental health treatment among medical and dental students. $J$ College Stud Psychother. 2000;14(3):23-39. doi:10.1300/ J035v14n03_05

9. Chew-Graham CA, Rogers A, Yassin N. "I wouldn't want it on my CV or their records": medical students' experiences of help-seeking for mental health problems. Med Educ. 2003;37(10):873-880. doi:10.1046/j.1365-2923.2003.01627.x

10. Czyz EK, Horwitz AG, Eisenberg D, Kramer A, King CA. Selfreported barriers to professional help seeking among college students at elevated risk for suicide. $J$ Am Coll Health. 2013;61(7):398-406. doi:10.1080/07448481.2013.820731

11. Curtis C. Youth perceptions of suicide and help-seeking: "they'd think I was weak or 'mental."'. J Youth Stud. 2010;13(6):699-715. doi:10.1080/13676261003801747

12. Downs MF, Eisenberg D. Help seeking and treatment use among suicidal college students. $J$ Am Coll Health. 2012;60(2):104-114. doi:10.1080/07448481.2011.619611

13. Mahfouz MS, Aqeeli A, Makeen AM, et al. Mental health literacy among undergraduate students of a Saudi tertiary institution: a cross-sectional study. Ment Illn. 2016;8(2):6806. doi:10.4081/ mi.2016.6806

14. Almaghaslah D, Alsayari A. The effects of the 2019 novel coronavirus disease (COVID-19) outbreak on academic staff members: a case study of a pharmacy school in Saudi Arabia. Risk Manag Healthc Policy. 2020;13:795-802. doi:10.2147/RMHP.S260918

15. Wilson CJ, Deane FP, Ciarrochi J. Measuring help seeking intentions: properties of the general help seeking questionnaire. Can J Couns. 2005;39(1):15-28. 


\section{Publish your work in this journal}

Risk Management and Healthcare Policy is an international, peerreviewed, open access journal focusing on all aspects of public health, policy, and preventative measures to promote good health and improve morbidity and mortality in the population. The journal welcomes submitted papers covering original research, basic science, clinical \& epidemiological studies, reviews and evaluations, guidelines, expert opinion and commentary, case reports and extended reports. The manuscript management system is completely online and includes a very quick and fair peer-review system, which is all easy to use. Visit http://www.dovepress.com/testimonials.php to read real quotes from published authors. 